\title{
Enrichment of Artemia (Leach) Nauplii with Canola Oil: Effect on Heros severus (Heckel) Larvae Performance and Environmental Stress
}

\author{
Javad Motamedi Tehrani ${ }^{*}$, Eisa Ebrahimi Dorche1, Sayed Amir Hosein Goli², \\ Paria Akbary ${ }^{3}$ \\ ${ }^{1}$ Department of Natural Resources, Isfahan University of Technology, Isfahan, Iran \\ ${ }^{2}$ Department of Agriculture, Isfahan University of Technology, Isfahan, Iran \\ ${ }^{3}$ Department of Marine Sciences, Fisheries Group, Chabahar Maritime University, Chabahar, Iran \\ Email: ${ }^{\text {jimotamedi124@gmail.com }}$
}

Received 24 October 2014; revised 30 November 2014; accepted 19 December 2014

Copyright (C) 2014 by authors and Scientific Research Publishing Inc.

This work is licensed under the Creative Commons Attribution International License (CC BY). http://creativecommons.org/licenses/by/4.0/

(c) (i) Open Access

\section{Abstract}

The effect of canola oil enriched Artemia (Leach) nauplii on growth, survival, resistance to environmental stresses of temperature and oxygen deficiency and fatty acid composition in severum fish, Heros severus (Heckel), larvae were investigated. The larvae (average weight $3 \mathrm{mg} \pm 0.83$ ) were fed 4 times daily starting at the onset of exogenous feeding for 18 days. Triplicate groups of fish were offered one of two treatments: 1) newly hatched Artemia (Leach) nauplii (unenriched) and 2) canola oil enriched Artemia (Leach) nauplii. Then all groups of fish were switched to the commercial diet for an additional period of 18 days. Statistical analysis of growth after 18 days and at the end of the experiment (36 days), showed that the highest specific growth rates $(9.65 \% \pm$ $0.3),(17.44 \% \pm 0.31)$ the average weight $(17 \mathrm{mg} \pm 0.95),(65.2 \mathrm{mg} \pm 0.53)$ were observed in treatment 2 respectively, but there was no significant difference in survival rate between treatments. The best result of resistance to oxygen deficiency $(5 \mathrm{~min}$ ) was observed in larvae reared on treatment 2 with $75.67 \% \pm 0.66$ after 36 days. Result of temperature stress showed no significant difference between treatments. The larvae were also found to convert n-3 fatty acids to EPA and DHA.

\section{Keywords}

Canola Oil, Heros severus, Growth, Survival, EPA, DHA

\footnotetext{
${ }^{*}$ Corresponding author.
} 


\section{Introduction}

Successful rearing of larval fish is the most critical stage in the production cycle for many species. Heros severus (Heckel) is a freshwater tropical cichlid native to the Amazon region in South America and Singapore in Southeast Asia [1]. Since no artificial feed formulation is yet available to completely substitute for Artemia (Leach), feeding live prey to young fish larvae still remains essential in commercial hatchery operations [2].

The use of Artemia (Leach) nauplii is well established due to its many advantages: year-round availability as on-the shelf cysts; good nutritional value for some fish; and relatively easy improvement through simple enrichment techniques [3]. Nutritional deficiencies have been another concern when using brine shrimp. Some stocks of Artemia (Leach) nauplii have shown a deficiency in eicosapantaenoic acid (EPA; 20:5n-3) and doccosahexanoic acid (DHA; 22:6n-3) [4]. The essential fatty acids (EFA) for fish are broadly recognized to comprise polyunsaturated fatty acids (PUFA) with carbon chain lengths of 18 and HUFA with carbon chain lengths of 20 and 22, of both the n-3 and n-6 series. Hence, these fatty acids must be provided in the diet to meet the fish's requirements. Several studies have demonstrated the positive effect of enriched live food on the growth, survival performance of various aquaculture species [5]-[7]. Also use of Artemia (Leach) enriched with long-chain unsaturated fatty acids for larvae and fry develops non-specific mechanisms of fish immunity and increases their resistance to diseases and environmental stresses. Gapasin et al. [5] studied effect of live food enriched with fatty acid on fish (Chanos chanos (Forsskål)) and their role in increasing the stress resistance of larvae and Ashraf et al. [8] considered effect of enriched diet with fatty acids on the survival rate and salinity stress on the fish side Silverstein (Menidia beryllina (Cope)). Also in Iran, Noori et al. [7] studied the effect of enriched Artemia (Leach) with fatty acids on the resistance to salinity stress in Iranian stergeon fish, Acipencer persicus, (Borodin). Also, Sorgent et al. [9] reported that in freshwater fish, linolenic acid and linoleic acid are more than saltwater fish [9].

The name "canola" was chosen by the board of the Rapeseed Association of Canada in the 1970s. The "can" part stands for Canada and "ola" refers to oil. Canola was developed through conventional plant breeding from rapeseed. Rapeseed is the highest-producing oil seed crop in the United States. The major customers of canola seed are Japan, Mexico, China, and Pakistan, while the bulk of canola oil and meal goes to the United States, with smaller amounts shipped to Mexico, China, and Europe [10].

The objective of this study was to investigate canola oil in enhancing severum larval growth, survival and resistance to environmental stresses of temperature and oxygen deficiency and fatty acid composition temperature stress (up $24^{\circ} \mathrm{C}$ ).

\section{Material and Methods}

\subsection{Fish}

In July 2011, severum, Heros severus (Heckel), larvae at the first feeding stage (swim up) were purchased from Spanta Co., Mahyana Ryapars, Iran, and transferred in the Fisheries Laboratory, Department of Natural Resources, Isfahan University of Technology. 480 uniformly sized yolk-sac larvae ( $3 \mathrm{mg} \pm 0.83$ ) were randomly divided into 6 groups (two treatments, three replicates) of 80 individuals. Fishes of each group were transferred in to a 35 liter tank. Aeration was applied through a number of narrow pipes terminating to bubbliers. Culture tanks were cleaned daily, and physic-chemical parameters were measured every morning prior to feeding. Water quality was maintained within optimum range: temperature $\left(27.1^{\circ} \mathrm{C} \pm 1^{\circ} \mathrm{C}\right)$, dissolved oxygen $(5.76 \pm 0.96$ $\mathrm{mg} / \mathrm{L}), \mathrm{pH}(8.43 \pm 0.59)$, total ammonia $(0.02 \mathrm{mg} / \mathrm{L})$, total hardness $\left(165 \pm 8 \mathrm{mg} / \mathrm{L} \mathrm{Caco}_{3}\right)$ and the photoperiod was set at 12L: 12D cycle (light period from 8 - 20 hours) and light intensity was kept at 40 lux at the tank surface. Dead larvae were removed twice daily and counted.

\subsection{Hatching and Enrichment of Artemia (Leach) Nauplii}

Artemia cysts (Urmia Lake, Iran) were hatched following standard procedures [11] [12]. Newly hatched Artemia (Instar I) nauplii (200,000 nauplii/L) were divided in batches in $5 \mathrm{~L}$ plexiglass tanks. The enrichment protocol followed the method of Clawson and Lovell [13]. $0.5 \mathrm{~g}$ of lecithin was dissolved in $100 \mathrm{ml} 50^{\circ} \mathrm{C}$ water and then $5 \mathrm{~g}$ canola oil was mixed it. It was homogenized using a blender and stored in the refrigerator for 1 week. 0.5 $\mathrm{mL}$ of the enrichment suspension (assuming a density of 200 Artemia per $\mathrm{mL}$ ) was added per liter to the incubation water at the onset of the enrichment period. Another $0.5 \mathrm{ml} / \mathrm{L}$ of the enrichment diet was added 12 hours before harvesting and nauplii were harvested after 24 hours [14]. Newly hatched Artemia nauplii served as the 
control [3].

\subsection{Treatments}

After 7 days of acclimation to the condition, fish were divided in two treatments (in a completely randomized design with 3 replicates per treatment) were: 1) larvae fed newly hatched Artemia nauplii and 2) larvae fed canola oil enriched Artemia nauplii. The fish larvae in all treatments were fed 4 times per day for 18 days. Then all groups of fish were switched to the commercial diet for an additional period of 18 days.

\subsection{Sampling}

Feeding was stopped six hours prior to sampling fish for chemical analysis, survival and growth measurement on days 18 and 36. All fish from each replicate were harvested at weekly intervals, bulk-weighted and the total length (TL) was taken. The amount of feed given per group was recorded and used to calculate feed conversion ratios (FCR) [15]. Ninety fish per treatment (30 fish per replicate tank) and 3 replicate of enriched and unenriched Artemia nauplii (200 thousand Artemia nauplii for each replicate) were randomly collected on days 7 and 28. Samples were oven-dried at $60^{\circ} \mathrm{C}$ for $24 \mathrm{~h}$ then stored at $-20^{\circ} \mathrm{C}$. These dried samples were later analyzed for fatty acid methyl esters [16], using gas chromatography (GC) (Agilent 6890N). Results were expressed as \% total body dry weight. Also the number of surviving fish was recorded and used for calculating mortality. At the end of feeding trial all fish each tank were taken and their weights and lengths were measured. Specific growth rates (SGR), feed conversion ratios (FCR) and survival rate were calculated as following:

$\mathrm{SGR}=100 \times($ Ln final weight - Ln initial weight $) /$ day [17]

FCR $=$ feed intake (g)/weight gain (g) [15]

Survival $=100 \times($ initial fish number - dead fish number $) /($ initial fish number $)$

\subsection{Resistance to Environmental Stresses}

Thirty severum larvae were subjected to temperature stress test following the method described by [18] [19]. The test involved immersing fish, 10 fish larvae/replicate in $34^{\circ} \mathrm{C}$ (as high temperature) and $16^{\circ} \mathrm{C}$ (as low temperature) for a period of one hour. Sixty severum larvae (20 larvae/replicate) of each treatment were exposed for 2 and 5 min under low oxygen tension [18] [19]. The mortality was recorded at every $1 \mathrm{~h}$ interval sup to $24 \mathrm{~h}$.

\subsection{Statistical Analysis}

At the end of the experiment the number of surviving fish was recorded and used for calculating mortality. Diet effects on total length, SGR, FCR, survival, weight, and environmental stress were analyzed using independent $\mathrm{T}$ test at confidence level 5\% ( $\mathrm{P}=0.05)$ (SPSS version 9).

\section{Results}

Fatty acid contents of newly hatched and enriched Artemia are shown in Table 1. The individual fatty acid levels of linolenic $\left(\mathrm{w}_{3}\right)$ and linoleic $\left(\mathrm{w}_{6}\right)$ acid were consistently higher in the canola oilenriched nauplii than in the newly hatched nauplii. The HUFA and EPA levels $(2.15 \%$ and $2.15 \% \pm 0.07)$ were highest in newly Artemianauplii.

Fatty acid content of severum larvae is shown in Table 2. The EPA (3.37\% $\pm 0.07 \%)$ level in treatment 1 was generally high compared to treatment $2(2.8 \% \pm 0.25 \%)$. The PUFA level was significantly different in all treatments $(\mathrm{P}<0.05)$, with highest PUFA observed in treatment $2(\mathrm{P}<0.05)$. The HUFA level was high in treatment 1 (Table 2).

Fatty acid content of canola oil is shown in Table 3. The linoleic (18:2n-6) and linolenic acid (18:3n-3) levels in canola oil were generally high compared to EPA and DHA. The HUFA level was zero in canola oil.

Severum fedwith Artemia enriched with canola oil (treatment 2$)$ exhibited significantly higher $(\mathrm{P}<0.05)$ growth compared to treatment 1 (fed newly Artemia nauplii) after 18 and 36 days of culture (Table 4). After 36 days of culture, survival significantly differed among the treatments $(P<0.05)$. The highest survival was observed in treatment 1 (Table 4).

When 36-day-old severum were subjected to temperature stress, mortality rate of the severum fed with Artemia 
Table 1. Certain fatty acids (\%) of newly Artemia nauplii (A), Artemia enriched with canola oil (B).

\begin{tabular}{ccc}
\hline Fatty acid & A & B \\
$14: 0$ & $\operatorname{tr}$ & $\operatorname{tr}$ \\
$14: 1 \mathrm{n}-5$ & $\operatorname{tr}$ & $\operatorname{tr}$ \\
$16: 0$ & $0.01^{\mathrm{a}} \pm 19.5$ & $0.005^{\mathrm{b}} \pm 21.3$ \\
$16: 1 \mathrm{n}-7$ & $0.01^{\mathrm{b}} \pm 3.49$ & $0.007^{\mathrm{a}} \pm 16$ \\
$18: 0$ & $0.03^{\mathrm{a}} \pm 6.9$ & $0.007^{\mathrm{b}} \pm 11.35$ \\
$18: 1 \mathrm{n}-9$ & $0.03^{\mathrm{b}} \pm 18.73$ & $0.005^{\mathrm{a}} \pm 15.62$ \\
$18: 2 \mathrm{n}-6$ & $0.14^{\mathrm{a}} \pm 5.1$ & $0.03^{\mathrm{b}} \pm 6.5$ \\
$18: 3 \mathrm{n}-3$ & $0.49^{\mathrm{a}} \pm 29.52$ & ${ }^{\mathrm{b}} 0.07 \pm 41.72$ \\
$20: 0$ & $\operatorname{tr}$ & $\operatorname{tr}$ \\
$20: 1 \mathrm{n}-9$ & $\operatorname{tr}$ & $\operatorname{tr}$ \\
$20: 2 \mathrm{n}-6$ & $\operatorname{tr}$ & $\operatorname{tr}$ \\
$20: 3 \mathrm{n}-3$ & $\operatorname{tr}$ & $\operatorname{tr}$ \\
$20: 4 \mathrm{n}-6$ & $\operatorname{tr}$ & $\operatorname{tr}$ \\
$(20: 5 \mathrm{n}-3)($ EPA $)$ & $0.07^{\mathrm{b}} \pm 2.15$ & $0^{\mathrm{a}}$ \\
$(22: 6 \mathrm{n}-3)($ DHA $)$ & 0 & $\operatorname{tr}$ \\
SFA $\sum$ & $26.4^{\mathrm{a}}$ & $65^{\mathrm{b}} .32$ \\
USFA $\sum$ & $22.19^{\mathrm{a}}$ & $17.22^{\mathrm{b}}$ \\
PUFA $\sum$ & $34.62^{\mathrm{a}}$ & $48.22^{\mathrm{b}}$ \\
HUFA $\sum$ & $2.15^{\mathrm{b}}$ & $0^{\mathrm{a}}$ \\
\hline
\end{tabular}

Values in each row with different superscripts are significantly different $(\mathrm{P}<0.05)$. Data are mean $\pm \mathrm{SD}(\mathrm{n}=3)$; SFA $=$ saturated fatty acid; USFA = unsaturated fatty acid; HUFA = highly unsaturated fatty acid and PUFA = poly unsaturated acid; tr = trace.

Table 2. Whole-body fatty acid composition (\%) of 18-day old severum larvae fed of different diets.

\begin{tabular}{ccc}
\hline Fatty acid & Treatment 1 & Treatment 2 \\
$14: 0$ & $\operatorname{tr}$ & $\operatorname{tr}$ \\
$14: 1 \mathrm{n}-5$ & $\operatorname{tr}$ & $\operatorname{tr}$ \\
$16: 0$ & $26.29 \pm 0.43^{\mathrm{b}}$ & $25.20 \pm 0.012^{\mathrm{a}}$ \\
$16: 1 \mathrm{n}-7$ & $2.29 \pm 0.01^{\mathrm{a}}$ & $2.50 \pm 0.007^{\mathrm{a}}$ \\
$18: 0$ & $21.07 \pm 0.19^{\mathrm{b}}$ & $17.80 \pm 0.23^{\mathrm{a}}$ \\
$18: 1 \mathrm{n}-9$ & $22.23 \pm 0.04^{\mathrm{a}}$ & $23.04 \pm 0.04^{\mathrm{b}}$ \\
$18: 2 \mathrm{n}-6$ & $4.78 \pm 0.01^{\mathrm{a}}$ & $5.93 \pm 0.06^{\mathrm{b}}$ \\
$18: 3 \mathrm{n}-3$ & $3.61 \pm 0.007^{\mathrm{a}}$ & $5.98 \pm 0.01^{\mathrm{b}}$ \\
$20: 0$ & $\operatorname{tr}$ & $\operatorname{tr}$ \\
$20: 1 \mathrm{n}-9$ & $\operatorname{tr}$ & $\operatorname{tr}$ \\
$20: 2 \mathrm{n}-6$ & $\operatorname{tr}$ & $\operatorname{tr}$ \\
$20: 3 \mathrm{n}-3$ & $\operatorname{tr}$ & $\operatorname{tr}$ \\
$20: 4 \mathrm{n}-6$ & $\operatorname{tr}$ & $2.80 \pm 0.25^{\mathrm{a}}$ \\
$(20: 5 \mathrm{n}-3)(\mathrm{EPA})$ & $3.37 \pm 0.075^{\mathrm{b}}$ & $16.53 \pm 0.01^{\mathrm{a}}$ \\
$(22: 6 n-3)($ DHA $)$ & $16.33 \pm 0.03^{\mathrm{a}}$ & $43^{\mathrm{a}}$ \\
SFA $\sum$ & $47.36^{\mathrm{b}}$ & $25.54^{\mathrm{b}}$ \\
USFA $\sum$ & $24.52^{\mathrm{a}}$ & $11.91^{\mathrm{b}}$ \\
PUFA $\sum$ & $8.39^{\mathrm{a}}$ & $19.33^{\mathrm{a}}$ \\
HUFA $\sum$ & $19.7^{\mathrm{b}}$ & $\mathrm{tan}$
\end{tabular}

Values in each row with different superscripts are significantly different $(\mathrm{P}<0.05)$. Treatment 1 : severum larvae fed with newly Artemianauplii; Treatment 2: severum larvae fed with Artemia enriched with canola oil; $\mathrm{Tr}=$ trace. 
Table 3. Certain fatty acids (\%) of canola oil.

\begin{tabular}{|c|c|}
\hline Fatty acid & Canola oil \\
\hline $14: 0$ & 0 \\
\hline 16: 0 & 5.77 \\
\hline 18: 0 & 1.27 \\
\hline Other SFA & 4.76 \\
\hline $\mathrm{SFA} \sum$ & 11.80 \\
\hline 18: $1 \mathrm{n}-9$ & 77.33 \\
\hline Other MUFA & 0.58 \\
\hline MUFA $\sum$ & 77.91 \\
\hline 18: $2 n-6$ & 1.01 \\
\hline 18: 3n-6 & 0.38 \\
\hline $20: 3 n-6$ & $\operatorname{tr}$ \\
\hline $20: 4 n-6$ & $\operatorname{tr}$ \\
\hline Other PUFA n-6 & 0.14 \\
\hline PUFA n-6 $\sum$ & 1.53 \\
\hline 18: 3n-3 & 7.05 \\
\hline 18: $5 n-3$ & $\operatorname{tr}$ \\
\hline $22: 5 n-3$ & $\operatorname{tr}$ \\
\hline $22: 6 n-3$ & $\operatorname{tr}$ \\
\hline Other PUFA n-3 & 1.71 \\
\hline$\sum$ PUFA n-3 & 8.76 \\
\hline
\end{tabular}

Table 4. Average total weight and length ${ }^{\mathrm{a}}$, Specific growth rate (SGR), food conversion ratio (FCR) and percent survival of fish fed various dietary treatments. Values are mean \pm standard deviation $(\mathrm{n}=10)$.

\begin{tabular}{ccccccc}
\hline Treatment & Time (day) & Average weight (mg) & Average total length (mm) & FCR & SGR (\%) & Survival (\%) \\
\hline 1 & 18 & $13.5 \pm 0.75^{\mathrm{a}}$ & $7.42 \pm 0.63^{\mathrm{a}}$ & - & $8.31 \pm 0.33^{\mathrm{a}}$ & $81.87 \pm 0.29^{\mathrm{a}}$ \\
2 & 18 & $17.1 \pm 0.95^{\mathrm{b}}$ & $9.34 \pm 0.44^{\mathrm{b}}$ & - & $9.65 \pm 0.30^{\mathrm{b}}$ & $80.04 \pm 2.24^{\mathrm{a}}$ \\
1 & 36 & $37.50 \pm 037^{\mathrm{a}}$ & $13.84 \pm 1.09^{\mathrm{a}}$ & $4.18 \pm 0.2^{\mathrm{b}}$ & $5.37 \pm 0.47^{\mathrm{b}}$ & $96 \pm 1.09^{\mathrm{a}}$ \\
2 & 36 & $65.20 \pm 5.70^{\mathrm{b}}$ & $14.17 \pm 0.55^{\mathrm{b}}$ & $3.27 \pm 0.15^{\mathrm{a}}$ & $7.44 \pm .53^{\mathrm{a}}$ & $100^{\mathrm{b}}$ \\
\hline
\end{tabular}

Within columns values with different superscripts are significantly different $(\mathrm{P}<0.05)$. ${ }^{\mathrm{a}}$ Initial weights and lengths of severum larvae $3(\mathrm{mg}) \pm 0.83 \mathrm{SD}$ and $6.82(\mathrm{~mm}) \pm 0.83$ SD respectively.

enriched with canola oil (treatment 2) and newly Artemia nauplii (treatment 1) was no significant difference (P > 0.05) in temperature $16^{\circ} \mathrm{C}$ and $34^{\circ} \mathrm{C}$ (Table 5). The highest mortality was observed in treatment 1 . When 36days-old severum were exposed to oxygen deficiency $(5 \mathrm{~min})$, the survival rate was significantly high $(\mathrm{P}<0.05)$ in treatment $2(75.62 \% \pm 0.66 \%)$ compared to treatment $1(47.5 \% \pm 1.42 \%)$ after $24 \mathrm{~h}$ (Table 5).

\section{Discussion}

Several studies have demonstrated the positive effect of enriched live food on the growth performance of various species. HUFA-enriched Artemia nauplii fed to Fenneropenaeus indicus (H. Milne-Edwards), [20], Sepia 
Table 5. Results of temperature stress $\left(34^{\circ} \mathrm{C}\right.$ and $\left.16^{\circ} \mathrm{C}\right)$ and oxygen deficiency $(2$ and 5 min) on mortality rates of different treatments in 36-day-old severum.

\begin{tabular}{ccccc}
\hline & & \multicolumn{2}{c}{ Survival\% } & \\
\hline Treatment & Temperature $16^{\circ} \mathrm{C}$ & Temperature $34^{\circ} \mathrm{C}$ & Oxygen deficiency 2 min & Oxygen deficiency 5 min \\
1 & $100 \pm 0^{\mathrm{a}}$ & $100 \pm 0^{\mathrm{a}}$ & $100 \pm 0^{\mathrm{a}}$ & $47.5 \pm 1.42^{\mathrm{a}}$ \\
2 & $100 \pm 0^{\mathrm{a}}$ & $100 \pm 0^{\mathrm{a}}$ & $100 \pm 0^{\mathrm{a}}$ & $75.63 \pm 0.66^{\mathrm{b}}$
\end{tabular}

Within columns values with different superscripts are significantly different $(\mathrm{P}<0.05)$.

oficinalis (Linnaeus) [17], and Chanos chanos (Forsskål) [5] exhibited better growth and survival. Gilthead sea bream larvae also grow better if fed rotifers enriched with highly unsaturated n-3 HUFA [21]. Similar to the finding of Tamaru et al. and Hosseinpour et al. [22] in the present study significant differences were found in the growth of severum larvae fed different diets, larvae fed Artemia enriched with canola oil (treatment 2) exhibited significantly higher growth than larvae fed unenriched nauplii (treatment 1) after 36 days of culture (Table 4). Tamaru (1998) used Artemia nauplii enriched with different oils for the production of ornamental fish and significant influences obtained on the growth and survival $(\mathrm{P}<0.05)$. Smith et al. [23] with research on essential fatty acids in the diet Bidyanus bidyanus reported that linolenic acid in the diet increased fish growth rate.

On the other hand, survival of 36 days-old severum fed various diets was significantly different (Table 4). Mortality of the canola oil treated fish was significantly lower than unenriched nauplii fed fish supporting the results of Limanda ferruginea (D. H. Storer) [24], Peterophylum scalare (Schultze) [25] and Oncorhynchus mykiss (Walbaum) [26]. Akbary et al. [26] concluded that survival rate of rainbow trout larvae fed with enriched Artemia (HUFA + vitamin C) during 29 days of testing (96\%) is higher than larvae fed unenriched nauplii (84\%) and larvae were fed with commercial food (67\%). In the current investigation, the larvae fed by canola oil for 18 days exhibited more resistance to oxygen deficiency (Table 5), compared to treatment 1 . When subjected to temperature stress test, 36 days old Heros severus larvae fed canola oil Artemia exhibited no significant difference with larvae fed uneriched nauplii. The mortality in larvae fed enriched Artemia was lower than control Due to the high levels of linolenic acid in treatment 2 supporting the results of Smith et al. [23], Kiron et al. [4]. [4] reported that n-3 fatty acids are important precursors in the synthesis eicozanoids that is an important mediator in inflammatory reactions and immune responses. When dietary have a deficiency of essential fatty acid n-3, antibacterial activity of macrophage cells is reduced. If macrophages receive linolenic acid, their bactericidal ability will rise. Van Stappen [27] reported that freshwater species would need to the fatty acids linolenic and linoleic and Marine fish species would need to EPA and DHA.

Milkfish larvae given Artemia enriched with HUFA + vitamin C showed better growth and higher survival after a stress test [5]. Ako et al. [18], Gapasin et al. [5] observed no or few mortalities among fish fed Artemia enriched with menhaden oil (high DHA:EPA ratio) compared to high mortalities among fish fed unenriched Artemia. Red sea bream, Pagrus major, (Temminck \& Schlegel) and marble sole Euryglossa orientalis, (Bloch \& Schneider) larvae given diets containing DHA and lecithin tolerated temperature and salinity changes, low oxygen and air exposure better than the larvae given DHA and lecithin-free diets [28]. Furuita et al. [29] reported that yellowtail larvae and red sea bream juvenile fed Artemia enriched with DHA exhibited higher survival in the stress test than those fed Artemia enriched with EPA. In the present study, severum larvae fed Artemia enriched with canola oil (Treatment 2) showed better growth and increased resistance to oxygen deficiency than those given unenriched diet (treatment 1). This result is similar to Chanos chanos [5] Sepia officicinalis [17].

The preceding studies attest the importance of EFA and in fish growth and development. Severum fed with canola oil exhibited significantly $(\mathrm{P}<0.05)$ higher growth than those given unenriched live food after 36 days of culture. When subjected to oxygen deficiency, mortality of the canola oil treated fish was significantly lower (P $<0.05$ ) among the treatment groups. Optimum requirements of these nutrients in severum, however, are not yet known, using of Artemia enriched with long chain polyunsaturated fatty acids in proliferation centers of ornamental fish can increase fish resistance against stress-induced changes in environmental conditions.

\section{Acknowledgements}

The author thanks of the Shahidetebari Research Institute Isfahan University of technology for the financial support of this project. 


\section{References}

[1] Ebrahimi Dorche, E., Motamedi Tehrani, J., Hossein Goli, S.A., Akbari, P. and Nezameslami, A. (2013) Effect of Nauplii of Artemia urmiana Enriched with Flaxseed Oil on the Growth and Survival of Cichlasoma severum Larvae. Journal of Fisheries Sciences and Technology, 3, 1-15. (In Persian)

[2] Sorgeloos, P., Dhert, P. and Candreva, P. (2001) Use of Brine Shrimp Artemia spp., in Marine Fish Larviculture. Aquaculture, 200, 147-159. http://dx.doi.org/10.1016/S0044-8486(01)00698-6

[3] Leger, P., Bengston, D.A. and Sorgeloos, P. (1987) The Nutritional Value of Artemia. Artemia Research and Its Application, Vol. 3. Universa Press Wettern, Belgium, 357-370.

[4] Kiron, V., Fukuda, H., Takeuchi, T. and Watanabe, T. (1995) Essential Fatty Acid Nutrition and Defence Mechanisms in Rainbow Trout. Comparative Biochemistry and Physiology, 111, 361-367. http://dx.doi.org/10.1016/0300-9629(95)00042-6

[5] Gapasin, R.S.J., Bombeo, R., Lavens, P., Sorgeloos, P. and Nelis, H. (1998) Enrichment of Live Food with Essential Fatty Acids and Vitamin C: Effects on Milkfish (Chanos chanos) Larval Performanace. Aquaculture, 162, 269-286. http://dx.doi.org/10.1016/S0044-8486(98)00205-1

[6] Lim, L.C., Dhert, P., Chew, W.Y., Dermaux, V., Nelis, H. and Sorgeloos, P. (2002) Enhancment of Stress Resistance of Guppy Poecilia reticulate through Feeding with Vitamin C Supplement. Journal of the World Aquaculture Society, 33, 32-40. http://dx.doi.org/10.1111/j.1749-7345.2002.tb00475.x

[7] Noori, F., Azari Takami, G. and Sorgeloos, P. (2005) Enrichment of Artemia with Essential Fattyacids, Lipid Emulsion and Vitamin C and Its Effect on the Performance of Acipenser persicus Larvae under the Effect of Salinity Stress. 5th International Symposium on Sturgeon, Ramsar, 9-13.

[8] Ashraf, M., Bengtson, D.A. and Simpson, K.L. (1993) Effects of Dietary Fatty Acid Enrichment on Survival, Growth and Salinity-Stress-Test Performance of Inland Silversides. The Progressive Fish Culturist, 55, 280-283. http://dx.doi.org/10.1577/1548-8640(1993)055<0280:EODFAE>2.3.CO;2

[9] Halver, J.E. and Hardy, R.W. (2002) Fish Nutrition. In: Sargent, J.R., Tocher, D.R. and Bell, G., Eds., The Lipids, 3rd Edition, Academic Press, California, 182-246.

[10] Zeratsky, K. (2009) Canola Oil: Does It Contain Toxins? Mayo Clinic. Retrieved 10 August 2011.

[11] Sorgeloos, P., Lavens, P., Leger, Ph. and Tackaert, W. (1993) The Use of Artemia in Marine Fish Larviculture. Finfish Hatchery in Asia: Proceedings of Finfish Hatchery in Asia '91, TML Conference Proceedings, 3, 73-86.

[12] Lavens, P. and Sorgeloos, P. (1996) Manual on the Production and Use of Live Food for Aquaculture. FAO, Rome, 79-250.

[13] Clawson, J.A. and Lovell, R.T. (1992) Improvement of Nutritional Value of Artemia for Hybrid Stripped Bass/White Bass (Morone saxatilis $\times$ M. chrysops) Larvae by n-3 HUFA Enrichment of Nauplii with Menhaden Oil. Aquaculture, 108, 125-134. http://dx.doi.org/10.1016/0044-8486(92)90323-D

[14] Agh, N. and Noori, F. (1997) Introduction of a Parthenogenetic Population of Artemia from Lagoons around Urmia Lake and Its Morphological Comparison with Artemia Urmiana. In: Moellem, T., Ed., Proceedings of the First Iranian Congress of Zoology, University of Teacher Education, Tehran, 17-18 September 1997.

[15] Lara-Flors, M., Olvera-Novoa, M.A., Guzman-Mendez, B.E. and Lopez-Madrid, W. (2003) Use of Bacteria Streptococcus faecium and Lactobacillus acidophilus, and the Yeast Saccharomyces cerevisisa as Growth Promoters in Nile Tilapia (Oreochromis niloticus). Aquaculture, 216, 193-201. http://dx.doi.org/10.1016/S0044-8486(02)00277-6

[16] Goli, S.A., Mat Sahri, M. and Kadivar, M. (2008) Enzymatic Interesterification of Structured Lipids Containing Conjugated Linoleic Acid with Palm Stearin for Possible Margarine Production. European Journal of Lipid Science and Technology, 110, 1102-1108. http://dx.doi.org/10.1002/ejlt.200800134

[17] Koueta, N., Boucaud-Camou, E. and Noel, B. (2002) Effect of Enriched Natural Diet on Survival and Growth of Juvenile Cuttlefish Sepia officinalis L. Aquaculture, 203, 293-310. http://dx.doi.org/10.1016/S0044-8486(01)00640-8

[18] Ako, H., Tamani, C.S., Bass, P. and Lee, C.S. (1994) Enhancing the Resistance to Physical Stress in Larvae of Mugil cephalus (Linnaeus) by the Feeding of Enriched Artemia Nauplii. Aquaculture, 122, 81-90. http://dx.doi.org/10.1016/0044-8486(94)90336-0

[19] Meshkini, S. (2003) The Effect of Vitamin C-Enriched Artemia Urmianaon Growth, Survival and Resistance to Environmental Stresses. Ph.D. Thesis of Veterinary Sciences, Tehran University, Tehran, 139 p. (In Persian)

[20] Taiebi, A. (2001) Effects of Feeding with HUFA Enriched Artemia on Growth, Survival and Resistance Penaeus indicus Post Larva, to Salinity Stress. M.Sc. Thesis of Fisheris Sciences, Tehran University, Tehran, 63 p. (In Persian)

[21] Mourente, G., Rodriguez, A., Tocher, D.R. and Sargent, J.R. (1993) Effect of Dietary Docosahexenoic Acid (DHA;22:6n-3) on Lipid and Fatty Acid Compositions and Growth in Gilthead Sea Bream (Sparus aurata L.) Larvae during First Feeding. Aquaculture, 112, 79-98. http://dx.doi.org/10.1016/0044-8486(93)90160-Z 
[22] Hosseinpour, H., Hafezieh, M., Kamarudin, M.S., Bin Saad, C.R., Abd Sattar, M.K., Agh, N., Valinassab, T. and Sharifian, M. (2010) Effects of Enriched Artemia Urmiana with HUFA on Growth, Survival, and Fatty Acids Composition of the Persian Sturgeon Larvae (Acipenser persicus). Iranian Journal of Fisheries Sciences, 9, 61-72.

[23] Smith, D.M., Hunter, B.J., Allen, G.L., Roberts, D.C.K., Booth, M.A. and Glecroos, B.D. (2004) Essential Fatty Acids in Diet on Silver Perch, Bidyanus bidyanus: Effect of Linolenic and Linoleic Acid on Growth and Survival. Aquaculture, 236, 377-390. http://dx.doi.org/10.1016/j.aquaculture.2003.10.021

[24] Rajkumar, M. and Kumaraguru vasagam, K.P. (2006) Suitability of the Copepod, Acartia cluasi as a Live Feed for Seabass Larvae (Lates calcarifer Bloch): Compared to Traditional Live-Food Organisms with Special on the Nutritional Value. Aquaculture, 261, 649-658. http://dx.doi.org/10.1016/j.aquaculture.2006.08.043

[25] Yaghoubi, M. (2011) Effect of Enrichment of Artemia Nauplii with HUFA on Growth, Survivaland Resistance to Environmental Stress in Larvae of Angel Fish (Peterophylum scalare). M.Sc. Thesis, Department of Natural Resources, Isfahan University of Technology, Isfahan, 56 p. (In Persian)

[26] Akbary, P., Hosseini, S.A. and Imanpoor, M.R. (2011) Enrichment of Artemia Nauplii with Essential Fatty Acids and Vitamin C: Effect on Rainbow Trout (Oncorhynchus mykiss) Larvae Performance. Iranian Journal of Fisheries Sciences, 10, 557-569.

[27] Van Stappen, G. (1996) Artemia. In: Lavens, P. and Sorgeloos, P., Eds., Manual on the Production and Use of Live Food for Aquaculture, FAO Publication, 101-318.

[28] Kanazawa, A. (1995) The Effects of Docosahexaenic Acid and Phospholipids on Stress Tolerance of Fish Larvae. In: Larvens, P., Jaspers, E. and Roelants, I., Eds., Larvi Fish and Shellfish, Larviculture Symposium, European Aquaculture Society, Special Publication, No. 24, Ghent, 105 p.

[29] Furuita, H., Konishi, K. and Takeuchi, T. (1999) Effect of Different Levels of Eicosapentaenoic Acid and Docosahexaenoic Acid in Artemia Nauplii on Growth, Survival and Salinity Tolerance of Larvae of the Japanese Flounder (Paralichthys oliaceus). Aquaculture, 170, 59-69. http://dx.doi.org/10.1016/S0044-8486(98)00386-X 
Scientific Research Publishing (SCIRP) is one of the largest Open Access journal publishers. It is currently publishing more than 200 open access, online, peer-reviewed journals covering a wide range of academic disciplines. SCIRP serves the worldwide academic communities and contributes to the progress and application of science with its publication.

Other selected journals from SCIRP are listed as below. Submit your manuscript to us via either submit@scirp.org or Online Submission Portal.
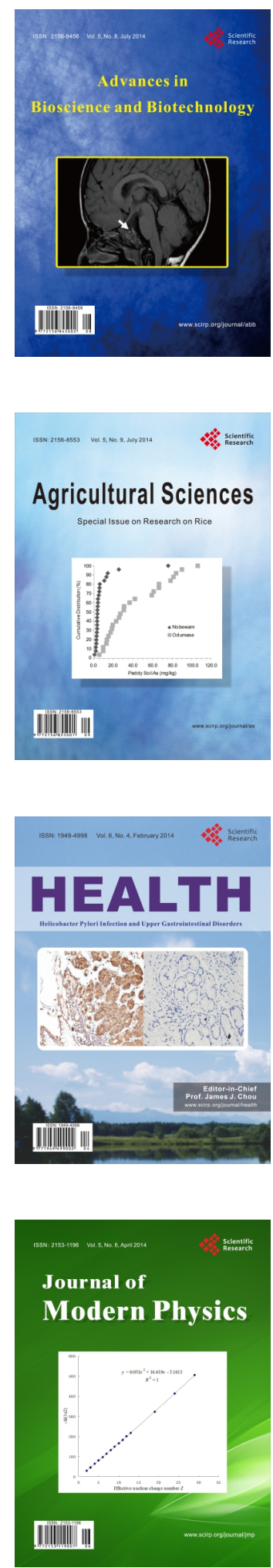
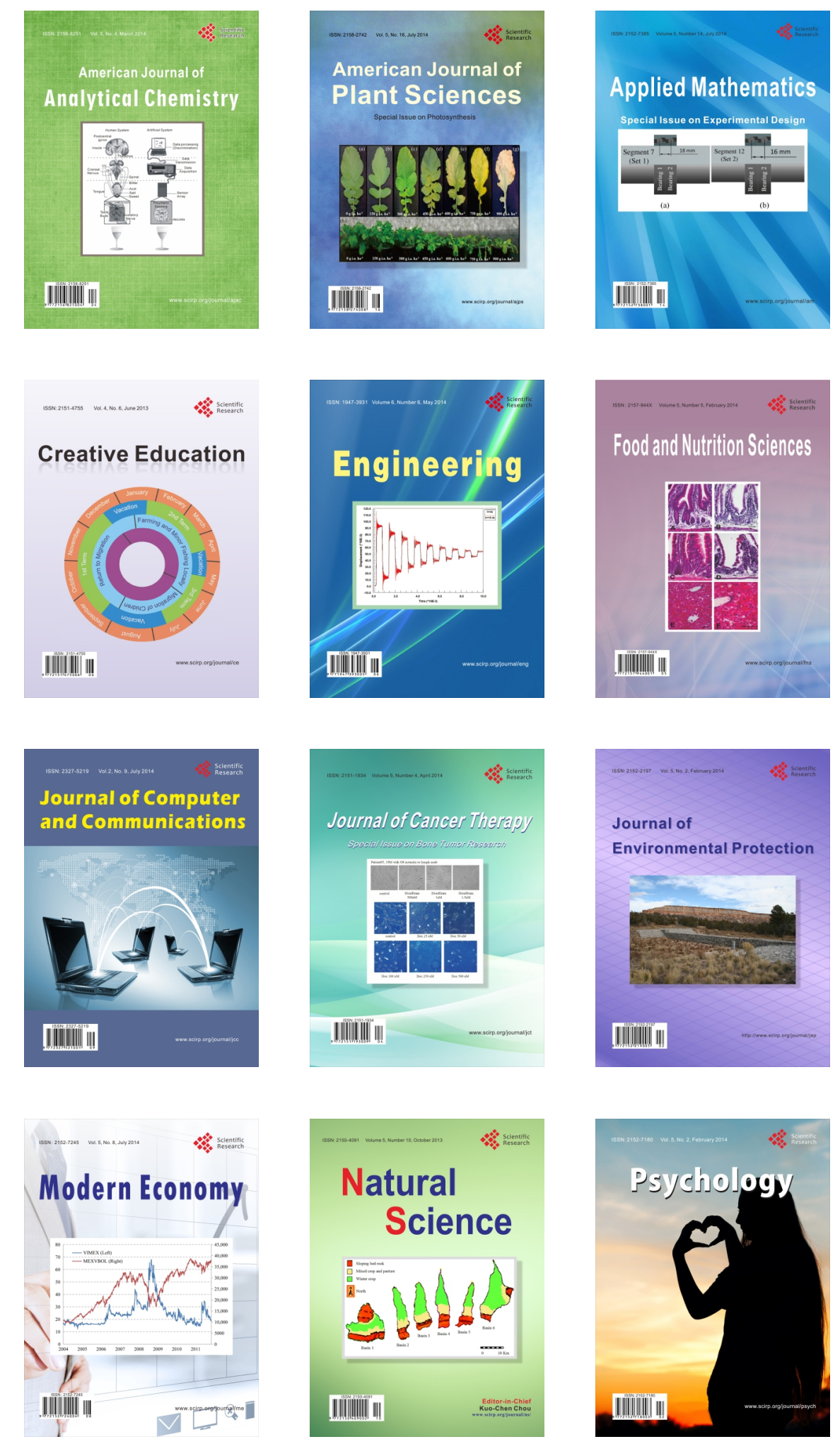